\title{
AI-BASED LEGAL TECHNOLOGY: A CRITICAL ASSESSMENT OF THE CURRENT USE OF ARTIFICIAL INTELLIGENCE IN LEGAL PRACTICE
}

by

JANA SOUKUPOVÁ*

In recent years, disruptive legal technology has been on the rise. Currently, several AI-based tools are being deployed across the legal field, including the judiciary. Although many of these innovative tools claim to make the legal profession more efficient and justice more accessible, we could have seen several critical voices against their use and even attempts to ban these services. This article deals with the use of artificial intelligence in legal technology and offers a critical reflection on the current state of the art. As much as artificial intelligence proved that it could improve the legal profession, there are still some underlying risks connected to the technology itself, which may deem its use disturbing.

\section{KEY WORDS}

Legaltech, Legal Technology, Artificial Intelligence, Provision of Legal Services, Robojudge

\section{INTRODUCTION}

In the past years, the use of disruptive technologies has found its way into the legal profession. Legal technology, or shortly "legaltech", refers to implementing various innovative technologies in the legal profession. ${ }^{1}$ Claims about better, cheaper, and faster services have become the leading marketing claims of many such services. These technological improvements

soukupovaj@prf.cuni.cz, Ph.D. student at Centre for Legal Skills, Charles University, Faculty of Law, Prague, Czech Republic.

1 Corrales, M., Fenwick, M., Haapio H. and Vermeulen, E. (2019) Tomorrow's Lawver Today? Platform-Driven LegalTech, Smart Contracts \& the New World of Legal Design. Journal of Internet Law, 22 (10), p. 6. 
did not only affect the private sector of legal services but have found their way into the field of the judiciary in some jurisdictions. This can be illustrated by an Estonian project, which aims to develop artificial intelligence (AI) software that would decide certain claims ${ }^{2}$ or by the infamous COMPAS software used in the United States to calculate the possibility of recidivism. ${ }^{3}$ The market currently offers many software tools whose aim is to improve the quality and effectiveness of the provision of legal services while using some of the presently popular technologies such as blockchain or AI. Although the former surprisingly found its use in areas such as a notary ${ }^{4}$, the latter has become popular across all legal fields. As a result, we can see many tools based on artificial intelligence whose aim is to help lawyers with drafting contracts, legal research, or perform due diligence. For example, Kira Systems provides a software based on machine learning called Kira which is designed to extract data, clauses and other provisions from documents. ${ }^{5}$ Likewise, Casetext developed an AI research tool called CARA A.I. that reviews cases included in legal documents.. ${ }^{6}$ Simultaneously, there are attempts to develop a software capable of predicting the court's decisions or tools to assist the judges with decisions on the cases. An example of this is a product offered by Lex Machina which works as a legal analytics tool for predicting litigation outcomes. ${ }^{7}$ Finally, there has been a rise in services that are aimed at the general public to provide them with better access to justice such as LegalZoom or DoNotPay. ${ }^{8}$

As a result of these technological opportunities, AI-based legaltech has a great potential of structurally changing all aspects of the law - starting

2 Niller, E. Can AI Be a Fair Judge in Court? Estonia Thinks So. [online] Wired. Available from: https://www.wired.com/story/can-ai-be-fair-judge-court-estonia-thinks-so/ [Accessed 26 February 2021].

3 Liu, H., Lin, C. and Chen, Y. (2018) Bevond State v. Loomis: Artificial Intelligence, Government Algorithmization, and Accountability. International Journal of Law and Information Technology, 27(2), pp. 122-141.

4 Kaczorowska, M. (2019) Blockchain-based Land Registration: Possibilities and Challenges. Masaryk University Journal of Law and Technology, 13 (2), pp. 339-360.

5 What is Kira. [online] Available from: https://kirasystems.com/how-kira-works/. [Accessed 5 June 2021].

6 CARA A.I. [online] Available from: https://casetext.com/cara-ai/. [Accessed 5 June 2021].

7 What we do. [online] Available from: https://lexmachina.com/about/. [Accessed 5 June 2021].

8 Marchant, G. (2017) Artificial Intelligence and the Future of Legal Practice. The SciTech Lawyer, 14 (1), p. 23. 
with legal education and ending with legal practice and judiciary. ${ }^{9}$ However, as opportunities grow, so does the critical response. Therefore, some authors such as Wendel, Sandvik, Yu or Pasquale pointed out the risk of new malpractice ${ }^{10}$, legal and technical black box connected to the use of $\mathrm{AI}^{11}$ or the all-embracing US-centrism. ${ }^{12}$ Another debate focuses on the barrier some of these services have to face in the form of statutes dealing with the unauthorized provision of legal services. ${ }^{13}$ Simultaneously, there is an ongoing debate on the use of artificial intelligence in the justice field and the right to a fair trial. ${ }^{14}$

As mentioned above, AI is capable of making significant changes in all areas of law. It is, however, known to have certain flaws, such as its lack of transparency and explainability, possible biases deriving from potentially flawed data, or highly techno "salvationist"15 narratives in its advertisement. This article addresses these risks connected to AI-based legaltech. The aim of this article is not to discourage the use of the new disruptive technologies but merely to offer a few points for reflection. While providing these points, I would like to stress that we should not uncritically embrace all AI-based legaltech in all possible areas of law and legal practice. Rather, we should examine the risks connected to each specific use as these risks might manifest differently with distinct $\mathrm{AI}$ tools and their distinct use. If a legal drafting tool makes a mistake, the consequences might be less severe than if a robojudge misjudges a piece of evidence. Hence, we should

9 McGinnis J. and Pearce, R. (2014) The Great Disruption: How Machine Intelligence Will Transform the Role of Lawyers in the Delivery of Legal Services. Fordham Law Review, 82 (6), p. 3042.

10 Sandvik, K. (2021) Is Legal Technology a New "Moment" in the Law and Development Traiectoru?. Tonlinel Antipode Online. Available from: httos://antipodeonline.org/2019/12/04/legal-technology-law-and-development/ [Accessed 26 February 2021].; Marchant, G. (2017) Artificial Intelligence and the Future of Legal Practice. The SciTech Lawyer, 14 (1), p. 23.

11 Liu, H., Lin, C. and Chen, Y. (2018) op. cit., pp. 134-136.; Wendel, B.W. (2019) The Promise and Limitations of Artificial Intelligence in the Practice of Law. Oklahoma Law Review, 72 (1), pp. 27-29.; Pasquale, F. (2019) A Rule of Persons, Not Machine: The Limits of Legal Automation. George Washington Law Review, 87 (1), p. 5.; Yu, R. and Spina G.A. (2019) What's Inside the Black Box? AI Challenges for Lawyers and Researchers. [online] Cambridge University Press. Available from: https://www.cambridge.org/core/journals/legalinformation-management/article/whats-inside-the-black-box-ai-challenges-for-lawyers-andresearchers/8A547878999427F7222C3CEFC3CE5E01\#article [Accessed 29 May 2021].

12 Sandvik, K. (2021) op. cit. Available from: httos://antipodeonline.org/2019/12/04/legaltechnology-law-and-development/ [Accessed 26 February 2021].

13 McGinnis J. and Pearce, R. (2014) op. cit., p. 3057.

14 Sourdin, T. (2018) Judge v Robot? Artificial Intelligence and Judicial Decision-Making. UNSW Law Journal, 41 (4).

15 Pasquale, F. (2019) op. cit., p. 2. 
be ready to know where to draw a line. Not all AI is equal when it comes to its risks and not all legal fields and services are the same.

The article consists of two main parts. The first part discusses the current concerns associated with AI and their significance for legaltech. The second part then focuses on AI's use in two particular legal areas: in the provision of legal services and in the judiciary. Specifically, the article separately explores and reflects the issues, themes, dilemmas, and impact of AI in these legal areas.

\section{THE RISKY ARTIFICIAL INTELLIGENCE AND LEGALTECH}

\subsection{AI-BASED LEGALTECH}

There have been many attempts to define what artificial intelligence is. Many scholars tried to come up with their own definition, often including terms such as the ability to learn, ability to reach any goal, consciousness, self-awareness or alternatively trying to tie artificial intelligence with the concept of intelligence or rationality. ${ }^{16}$ Calo, for example, understands $\mathrm{AI}$ as

$$
\begin{aligned}
& \text { "a set of techniques aimed at approximating some aspect of human or animal } \\
& \text { cognition using machines."17 }
\end{aligned}
$$

Scherer defined AI for his purposes as

"machines that are capable of performing tasks that, if performed by a human, would be said to require intelligence."

This is just a small demonstration of how diversely AI can be grasped. Thus, for the purpose of this article, artificial intelligence will be used as a broad umbrella term to cover a vast spectrum of technology often based on algorithms capable of achieving complex goals ${ }^{19}$, irrespective of whether the technology is based on machine learning, natural language processing, deep learning, or cognitive computing. This allows for

${ }^{16}$ Scherer, M. (2016) Regulating Artificial Intelligence Systems: Risks, Challenges, Competencies, and Strategies. Harvard Journal of Law \& Technology, 29 (2), pp. 360-361.

${ }_{17}$ Calo, R. (2018) Artificial Intelligence Policy: A Primer and Roadmap. University of Bologna Law Review, 3 (2), p. 184.

${ }_{18}$ Scherer, M. (2016) op. cit., p. 362.

19 Similar solution was adopted e.g., by Sourdin in Sourdin, T. (2018) Judge v Robot? Artificial Intelligence and Judicial Decision-Making. UNSW Law Journal, 41 (4), p. 1116. 
an extensive amount of legaltech to be covered. AI-based legaltech then refers to tools designed to achieve certain goals to improve legal services while using artificial intelligence. In practice, it may be either tools used for document revision, legal research, or even tools capable of predicting courts' decisions and the ones that are designed to assists judges with their decisions. ${ }^{20}$ And although lawyers still might be far from being replaced by robots, it seems that artificial intelligence may do certain tasks faster as it can process large volumes of data in a matter of seconds. ${ }^{21}$

\subsection{THE RISKS ASSOCIATED WITH ARTIFICIAL INTELLIGENCE}

AI offers many opportunities, most often connected to better efficiency. However, there are still many risks and dilemmas surrounding this technology. That is why it got on the radar of so many scholars and regulatory bodies recently. For example, in 2020, the European Commission adopted White paper on artificial intelligence in which a risk-based approach toward future regulation of artificial intelligence was emphasized..$^{22}$ The following chapters explore multiple risks associated with AI-based legaltech, such as its unpredictability, algorithmic and data bias, advertisement, or lack of transparency.

\subsubsection{THE BLACK BOX AND EXPLAINABILITY OF AI}

One of the risks associated with artificial intelligence is undoubtedly it being a black box. That means we have become unable to understand its decision-making process. ${ }^{23}$ In this sense, black box is a metaphor being used to describe the difficulty to explain $\mathrm{AI} .{ }^{24}$ Interestingly, there can be many black-box problems for different stakeholders. Thus, the question of explainability may vary from "what" to "why" depending on the stakeholder. ${ }^{25}$ However, the core issue is the same - we cannot

20 Corrales, M., Fenwick, M., Haapio H. and Vermeulen, E. (2019) op. cit., p. 7.

${ }^{21}$ Fabian, S. (2020) Artificial Intelligence and the Law: Will Judges Runs on Punchcards?. Common Law Review, 16 (4), p. 4.

${ }^{22}$ European Commission (2020) White Paper On Artificial Intelligence - A European approach to excellence and trust, COM(2020) 65 final, 19 February 2020. Available from: https://ec.europa.eu/info/sites/i nfo/files/commission-white-paper-artificial-intelligence-feb2020_en.pdf [Accessed 5 March 2021].

23 Bathaee, Y. (2018) The Artificial Intelligence Black Box and the Failure of Intent and Causation. Harvard Journal of Law \& Technology, 31 (2), p. 905.

24 Zednik, C. (2019) Solving the Black Box Problem: A Normative Framework for Explainable Artificial Intelligence. Tonlinel. Philosophy \& Technology. Available from: https://doi.org/10.1007/s13347-019-00382-7 [Accessed 29 May 2021].

25 Zednik, C. (2019) op. cit. 
understand it, which means that we cannot predict and recognize its failures. ${ }^{26}$ Additionally, it is also important to highlight that not all AI techniques are equally unexplainable. The one technique mostly connected to black box is deep learning, which was even called the "particularly dark black box" ${ }^{27}$ This essentially means that not all AI is equally opaque. This aspect might be important in the moment we are choosing which AI we will put our trust into when it comes to decision making.

The reason why the lack of explainability of AI has become such a serious part of the discussion is simple - it is a question of trust. ${ }^{28}$ The way $\mathrm{AI}$ is deployed nowadays leads to the fact that we put a lot of trust into a system that may be unpredictable or unexplainable to us. And there are calls that if we cannot properly understand AI, at least at the same level as we understand humans, we should not use it. ${ }^{29}$ That is the reason why there is a demand for the creation of "explainable AI" that would make AI's opacity transparent..$^{30}$ This issue of trust and transparency is an important thing to consider while using in the legal field, especially in the field of justice. In this matter, Wendel writes about the core function of law which includes the need for justification for actions that may affect other's interests. ${ }^{31} \mathrm{He}$ even goes further stating that the core lawyering function is the connection between legal authority and the moral demand for accountability. ${ }^{32}$ This in itself poses problems when it comes to the lack of explainability of AI.

The black box issue discussed above is sometimes referred to as the "technical black box". ${ }^{33}$ However, is not the only black box associated with AI. AI was also called a "legal black box" in the literature. The notion of the legal black box refers to its opacity that crystallizes from its being proprietary software. ${ }^{34}$ In other words, the algorithms and data are often

\footnotetext{
${ }^{26}$ Knight, W. (2017) The Dark Secret at the Heart of AI. [online] MIT Technology Review. Available from: https://www.technologyreview.com/2017/04/11/5113/the-dark-secret-at-theheart-of-ai/ [Accessed 5 June 2021].

27 Ibid.

28 Ibid.

29 Knight, W. (2017) op. cit.

30 Zednik, C. (2019) op.cit.

31 Wendel, B.W. (2019) The Promise and Limitations of Artificial Intelligence in the Practice of Law. Oklahoma Law Review, 72 (1), p. 29.

32 Ibid.

${ }^{33}$ Liu, H., Lin, C. and Chen, Y. (2018) op. cit., pp. 134-136.

${ }^{34}$ Ibid.
} 
protected as trade secrets. ${ }^{35}$ Clearly, the solution here is to demand a transparent release of these algorithms. ${ }^{36}$ This demand is particularly strong in the field of justice as transparency poses one of the core values in the justice system. ${ }^{37}$ The problem is that a simple release of an algorithm might not bring the desired effects as will be described in the following chapter.

Both of these aspects of black box create a very paradoxical situation in the legal market. On the one hand, we see the advertisement about how the brand-new AI tools can make our lives easier, the legal practice faster, and the judicial decisions fairer. On the other, we may not really know the "how" and "why" behind it. Moreover, this could also mean that the program may function in a different way than it was initially intended. ${ }^{38}$ That, in itself, can bear horrible consequences in the legal field, as will be demonstrated in the following chapters of this paper.

\subsubsection{BIAS AND DISCRIMINATION}

Another known risk connected to the use of AI is a bias that can lead to discrimination. There have been numerous cases where this issue has occurred. Amazon, for example, had to deactivate its AI used for the hiring process because it heavily discriminated against women. ${ }^{39}$ In another known case, LinkedIn's search engine was suggesting a male version of a name if a user searched for a female. ${ }^{40}$ Likewise, facial recognition technology, which is often based on deep learning, has become notorious for being biased on ethical, gender and racial characteristics. ${ }^{41}$

\footnotetext{
${ }^{35}$ Yu, R. and Spina G.A. (2019) What's Inside the Black Box? AI Challenges for Lawvers and Researchers. [online] Cambridge University Press. Available from: https://www.cambridge.org/core/journals/legal-information-management/article/whatsinside-the-black-box-ai-challenges-for-lawyers-andresearchers/8A547878999427F7222C3CEFC3CE5E01\#article [Accessed 29 May 2021].

36 Ibid.

37 Prins, C. and van Ettekoven, B-I. (2018). Data analvsis, artificial intelligence and the judiciary system. In Mak V., Tiong Tjin Tai E., \& Berlee A. (Eds.), Research handbook in data science and law, Edward Elgar, p. 442

38 Bathaee, Y. (2018) op. cit., p. 907.

39 Dastin, J. (2018) Amazon scraps secret AI recruiting tool that showed bias against women. [online] Reuters. Available from: https://www.reuters.com/article/us-amazon-com-jobs-automationinsight-idUSKCN1MK08G [Accessed 5 March 2021].

40 Day, M. (2018) How LinkedIn's search engine may reflect a gender bias. [online] The Seattle Times. Available from: https://www.seattletimes.com/business/microsoft/how-linkedinssearch-engine-may-reflect-a-bias/ [Accessed 5 March 2021].

${ }^{41}$ Castelvecchi, D. (2020) Is facial recognition too biased to be let loose?. [online] nature. Available from: https://www.nature.com/articles/d41586-020-03186-4 [Accessed 5 March 2021].
} 
Generally, bias may appear either in algorithms or in the data. ${ }^{42}$ Both of these biases may be complementary to each other. The algorithms are not immune to the values of their creators and at the same time they are dependent on the datasets they were provided with. ${ }^{43}$ The risk here is that AI may emphasize all the existing bias in the code or in flawed data. ${ }^{44}$ There is even an argument that as long as AI derives its instructions from humans, it will always be inaccurate. ${ }^{45}$

Moreover, the issue with bias is tightly connected to both technical and proprietary legal black box and affects more fields than law as algorithms are now being used to decide everyday economic decisions across many institutions. Yet, the institutions using them, be it a bank or state authority, do not know how the decisions were derived and people are basically left in the dark with their "why" question. ${ }^{46}$ That is why there is such a strong call for algorithm transparency. However, there is a growing skepticism that transparency alone might not solve the issue itself until we reach explainable AI. ${ }^{47}$ To put it simply - just knowing the code and the data might not be enough to understand the decision.

Once aware of the risks, it can only be concluded that using AI technology in the legal field can easily cause more harm than good, notably if used unaware of the risks and without any critical assessment. The risks may, however, differ. In the case of legal tools developed for attorneys to use in their practice, the outcome may simply be that different legal research tools come up with different results. ${ }^{48}$ Although this may mean that owning a particular database may pose a competitive advantage in the legal profession, it is not an impediment to the use of AI in legal practice. Whereas in judiciary, this issue may again be against the very core values of justice system. ${ }^{49}$

42 Therefore we either speak of algorithmic bias or data bias as described by Yu, R. and Spina G.A. (2019) op. cit.

43 Yu, R. and Spina G.A. (2019) op. cit.

44 Ibid.

45 Davis J. P. (2019) Artificial Wisdom? A Potential Limit on AI in Law (and Elsewhere). Oklahoma Law Review, 72 (1), pp. 65-66.

46 Hao, K. (2020) The coming war on the hidden algorithms that trap people in poverty [online] MIT Technology Review. [online] MIT Technology Review. Available from: https://www.technologyreview.com/2020/12/04/1013068/algorithms-create-a-poverty-traplawyers-fight-back// [Accessed 5 June 2021].

$47 \mathrm{Yu}, \mathrm{R}$. and Spina G.A. (2019) op. cit.

$48 \mathrm{Up}$ to $40 \%$ cases may be unique to each database, more in $\mathrm{Yu}$, R. and Spina G.A. (2019) op. cit.

49 Pasquale, F. (2019) op. cit., p. 5. 


\subsubsection{MORE TROUBLE WITH DATA}

Data has become a powerful asset in the past years. It can be argued that even more powerful than algorithms themselves. This is very well illustrated by Norvig's famous quote that Google does not have better algorithms, just more data. ${ }^{50}$ Data may, indeed, be a good helper and may give us answers to understand many underlying patterns in our daily lives. This being transformed in the field of law - data may for example help us to better understand court rulings as we can extract some patterns from them like how the judges use law literature or how often the change in case law led to the amendment in legislation. ${ }^{51}$

The problem is that data may be inaccurate and incomplete. It was already mentioned that faulty data may carry biases which are then projected into the result. But that is not the only issue. Data may simply be wrong. And once they are wrong, so is the outcome they produce. ${ }^{52}$ Furthermore, one needs a huge amount of data to build their legaltech tool. This may be an obstacle for many startups to create functional legaltech tools. LexMachina was for example funded by many big technology companies such as Oracle, Microsoft, Apple or Intel. ${ }^{53}$ Data also seem to be the reason behind the downfall of ROSS Intelligence as the company was sued by Westlaw for scraping Westlaw's database. ${ }^{54}$ This demonstrates that some AI risks do not lie directly within the AI, but are connected to the environment it creates on the market.

There are two final remarks I would like to make. First, data do not know the context and do not know the story. Data can be wrongly used in a different context than they were collected for. ${ }^{55}$ Here is where

50 This quote can be found in Cleland, S. (2011) Google's "Infringenovation" Secrets [online] Forbes. Available from: https://www.forbes.com/sites/scottcleland/2011/10/03/googlesinfringenovation-secrets/?sh=5e00d3c930a6 [Accessed 5 June 2021]. It was also repeated by Schneider, G. (2018) European intellectual property and data protection in the digitalalgorithmic economy; a role reversal(?). Journal of Intellectual Property Law \& Practice, 13 (8), p. 231.

51 Prins, C. and van Ettekoven, B-J. (2018) op.cit., p. 435.

52 This issue is often referred to as "garbage in, garbage out". For more detailed assessment see Davis J. P. (2019) op. cit., pp. 65-66.

53 Katz, D. (2012) Quantitative Legal Prediction--or--How I Learned to Stop Worrying and Start Preparing for the Data-Driven Future of the Legal Services Industry. Emory Law Journal, 62 (4), p. 940.

54 Lancaster, Alaina. Judge Rejects ROSS Intelligence's Dismissal Attempt of Thomson Reuters Suit Over Westlaw Content. [online] Law.com. Available from: https://www.law.com/therecorder/2021/03/29/judge-rejects-ross-intelligences-dismissalattempt-of-thomson-reuters-suit-over-westlaw-content/ [Accessed 5 June 2021].

55 Prins, C. and van Ettekoven, B-J. (2018) op.cit., p. 439. 
the context and decisions come into play. As was mentioned - simple algorithmic and data transparency may not be sufficient. Hence, if we want to understand the code, we must look for far more than the data itself. ${ }^{56}$ Second, there is a privacy issue with data. The moral question here is whether client's data or court party's data can or even should be used to feed these algorithms and who then own this data. ${ }^{57}$ Although this topic is slightly out of the scope of this article, it is still one piece of a puzzle of the data controversy.

\subsection{THE MARKETING NARRATIVES SURROUNDING AI}

There is one final note to make about the risks associated with AI-based legaltech and that is a reflection of their marketing strategies. We may notice that the one thing the legaltech tools have in common is the narrative surrounding them, which often revolves around promises on improved lawyering, higher performance and better access to justice. ${ }^{58}$ For instance, Ravell has quite a textbook claim which states that they "build data-driven tools that help lawyers be better, faster, and more persuasive. “59 We must therefore make a careful look at these services and evaluate whether they can truly deliver what they claim. Some of these tools may be targeted at professionals who may take their claims a bit more reserved. Others, such as chatbots or automated legal documents services, are designed for the general public which might fall for these claims much more easily, especially when the price points may differ drastically from attorneys. This is not to say that all legaltech designed for the public cannot deliver great service and help those truly in need. However, it is still a business being offered in a competitive environment. And there already has been a case where these claims went too far when the company claimed to deliver service in a quality equal to an attorney. ${ }^{60}$

It is also true that AI has a big potential to bring great benefits into legal practice because it can help lawyers with their research, contract analysis

${ }^{56}$ Pasquale, F. (2020) Revisiting the Black Box Society by rethinking the political economy of big data. Big Data \& Society, 7 (2), p. 3.

57 Prins, C. and van Ettekoven, B-J. (2018) op.cit., p. 445.

58 Sandvik, K. (2021) op. cit. Available from: https://antipodeonline.org/2019/12/04/legaltechnology-law-and-development/ [Accessed 26 February 2021].

59 Our Story. [online] Available from: https://home.ravellaw.com/who-we-are. [Accessed 5 June 2021].

${ }_{60}$ The case at hand is a German case involving Wolters Kluwer and their service SmartLaw. More detailed analysis can be found in the following chapter. 
or draft review while observing patterns humans would simply overlook. ${ }^{61}$ These benefits could even transform the legal profession and open debates about new set of skills lawyers should have. We must, however, take a very realistic look at what it can really do to not fall into a trap of unrealistic expectations. Reading some of the advertising claims can awaken very utopistic pictures of the legal profession's future. This is why it is important to understand both advantages and disadvantages of AI-based technology.

\section{PROVISION OF LEGAL SERVICES IN THE CONTEXT OF THE NEW TECHNOLOGIES}

Currently, the market offers dozens of legaltech tools and services which are based on AI, mostly natural language processing tools based on machine learning. These services also have different target groups as some such as Kira or Case Mine are offered to assist lawyers and others like LegalZoom or JustFix to help the public with access to justice. The latter category seems to be the one that sparks the most controversies, as these services have been challenged with unauthorized practice of law. ${ }^{62}$ This is the reason why I will focus on them. As many of these services are becoming more and more autonomous, the question arises whether they could be considered a provision of legal services or not. Additionally, an important point to reflect is that these services are still a business in their nature. Thus, they may not be as salvationist as they tend to present themselves.

\subsection{CHATBOTS, AUTOMATED LEGAL DOCUMENTS AND THE PROVISION OF LEGAL SERVICES}

DoNotPay, a so-called "robot lawyer", is a chatbot that started as a service that provided help with appealing parking tickets. Currently, it can help customers contest almost anything - insurance claims, driving tests or cancelled flight tickets. ${ }^{63}$ What is interesting about the service is that it was not created by a lawyer. The founder was 17 years old when he first started this app that currently runs on the famous IBM Watson. ${ }^{64}$ DoNotPay is an example that $\mathrm{AI}$ creates new opportunities for people to get their legal matter resolved without talking to a lawyer. In essence, it is not a bad thing

\footnotetext{
Yu, R. and Spina G.A. (2019) op. cit.

McGinnis J. and Pearce, R. (2014) op. cit., p. 3057.

63 Information available from the introduction page of DoNotPay, section Features. Available from: https://donotpay.com. [Accessed 5 March 2021].
} 
since legal services may be expensive, which may discourage many people from seeking legal advice. As Moradian points out, legaltech comes most for those who cannot afford standard legal services. ${ }^{65}$ And this is exactly what DoNotPay claims to be their mission. ${ }^{66}$ What may become an issue is the expectation these people have when using such services. If we look at the advertisement of DoNotPay a bit more carefully, we can observe that it allows people to "fight corporations, beat bureaucracy and sue anyone at the press of a button. ${ }^{467}$ Moreover, they list "sue anyone" as one of their features. ${ }^{68}$ Although wrapped in the "cheaper and better alternative to a lawyer" narrative, this sue anyone button might become hazardous when in hands of consumers. As much appealing as it is, consumers may be left in the dark about their actual chances with their claim or about the potential risks associated with this service based on AI.

Advertisement is not the only controversy connected to DoNotPay and similar services. Given their nature, these services have drawn the attention of many Bar Associations and raised a question about what a provision of legal services is. The reason is simple - a consumer or a company provides these services with information or documents and an algorithm gives them an answer or a full legal document. In the US, a platform called LegalZoom has faced multiple suits regarding the unauthorized provision of legal services. Although the service is a mere automated document preparation, it very nicely illustrates some tendencies towards these services and raises questions concerning whom the restriction on the unauthorized practice of law is meant to protect. ${ }^{69}$ The reasons behind these claims may not be just the protections against unqualified legal advice, but it may serve as an anticompetition measure. ${ }^{70}$ LegalZoom's services are also not that different from

\footnotetext{
64 Krieger, M. (2019) Stanford student's quest to clear parking tickets leads to "robot lawyers. [online] The Mercury News. Available from: https://www.mercurynews.com/2019/03/28/joshua-browder-22-builds-robot-lawyers/ [Accessed 5 March 2021].

65 Moradian, J. (2020) A New Era of Legal Services: The Elimination of Unauthorized Practice of Law Rules to Accompany the Growth of Legal Software. William. E Mary Business Law Review, 12 (1), p. 249.

66 Terms of Service, section Introduction and Overview. [online] Available from: https://donotpay.com/learn/terms-of-service-and-privacy-policy/ [Accessed 5 June 2021].

${ }_{67}$ Information available from the introduction page of DoNotPay, section Features. Available from: https://donotpay.com. [Accessed 5 June 2021].

68 Ibid.

${ }^{69}$ Shipman, C. (2019) Unauthorized Practice of Law Claims Against LegalZoom - Who Do These Lawsuits Protect, and is the Rule Outdated?. Georgetown Journal of Legal Ethics, 32 (4), p. 940 .

70 Shipman, C. (2019) op. cit., p. 944.
} 
the one many chatbots offer as they generate documents, and their system contains responses from their clients, which in the actual suit was used by the North Carolina Bar Association to demonstrate that their service is similar to a lawyer interviewing a client. ${ }^{71}$ This case also led to a creation of a new law in North Carolina that ultimately stated that the practice of law

"does not include the operation of a Web site by a provider that offers consumers access to interactive software that generates a legal document based on the consumer's answers to questions presented by the software. ${ }^{172}$

Recently, there has been an interesting case in this area in Germany. This case has not only brought up the question of the nature of these services but the claims they make in their advertisement. Hamburg Bar Association sued a platform SmartLaw for the same reasons as LegalZoom was sued in the US - unauthorized provision of legal services. SmartLaw works as a generator of legal documents based on a Q\&A system. It was precisely the fact that the platform used a Q\&A system that has become the core issue in the dispute. The Bar argued that since the system does not offer simple templates to fill but creates the contracts specifically tailored to the customer based on answers concerning the subject matter, it amounts to an individual examination of a case that constitutes a provision of legal services. $^{73}$ The Bar also had a problem with the service's allegedly misleading advertisement as many claims about the quality "being the same as from an attorney" was made. ${ }^{74}$ Unfortunately, we still do not have a final verdict at this point as the first two instances reached an opposite decision, so the final decision now remains to the supreme court. However, if we look at both decisions closer, it is interesting to see how the courts' approach toward the Q\&A system differs. In the first instance, the court concluded that the provision of such a system amounts to the individual examination of the case because the platform generates the documents on a more individualized matter and thus offers a tailored solution to the customer. ${ }^{75}$ The second instance, however, considered that the software's programming always predetermines the final result, so the finalized legal document is still

71 Shipman, C. (2019) op. cit., p. 946; LegalZoom.com, Inc. v. N.C. State Bar (2014), No. 11CVS15111, WL 1213242, North Carolina Business Court.

72 Shipman, C. (2019) op. cit., p. 947.

7333 O 35/19, LG Köln, 8.10.2019.

${ }^{74}$ Ibid.

75 Ibid. 
routinized. ${ }^{76}$ Both courts, however, agreed that the advertising was misleading as it may create unrealistic expectations.

Regardless of the SmartLaw case final result, there are a few points we may take from this and other similar disputes. First, as much as it can be argued at this point that automated responses do not provide any individual examination of the case, this might not be true in the future with the current technological development. It is going to be very interesting to see where the technical development will go as these chatbots and other similar services become "smarter". We may even take a wild guess that at some point, they will be truly capable of making a genuinely individual examination of a case that even might amount to legal reasoning.

Second, these claims often come from bar associations which may indicate that the dispute is not solely about the protection of the consumers, but there are some competitive aspects in play.

Finally, as these services are primarily offered as a cheaper and more accessible alternative to a lawyer, we must further debate about their role in our society and what advantages and disadvantages they bring. As already mentioned, one of the issues with the SmartLaw case was the misleading advertisement of the whole service. Similarly, DoNotPay has its whole advertisement build around a "sue anyone" button on your phone. That is why we should take a very cautious approach to all those claims about quality being on par with an attorney or surpassing even. If we take a look at all the risks associated with $\mathrm{AI}$, the result is that a code may simply be flawed - with bias or wrong data. Therefore, these chatbots and other similar services are very reliant on the datasets they were created with. Furthermore, if a chatbot is not sufficiently "trained" in a certain matter, a blind trust by a laic public may lead to the client's harm. ${ }^{77}$ Another risk may be the fact that the service might not be subject to any confidentiality or conflict of interest rules. ${ }^{78}$ These risks then go against

${ }^{76}$ I-6 U 263/19, Oberlandesgericht Köln, 19.6.2020.

77 It should be noted that the general public might not be the only one who can fall victim to the unrealistic expectations the advertisement may create. This leads to the general issue that if the AI-based legaltech is not provided with sufficient data, it may later fail to deliver appropriate level of services. This brings us back to the fact that context matters when it comes to data or that different tools may come up different results based on their algorithm or datasets. Hence, different tools may lead a lawyer to different problematics and different cases. This may play a role in the delivery of their service. This, however, leads to another debate that would be more focused on the ethical aspect of legal practice and possibly a need for a change in law curriculums.

78 Moradian, J. (2020) op. cit., p. 256. 
the general narrative about better access to justice, for which many of these services are created.

One final note on this topic should be made. Although the points mentioned above are inclining toward the critical view of these services, they still play an important role in the development of the legal profession. The points simply lead to the question we should ask ourselves - are these issues sufficiently adverse that we should fight for the ban of such services? My answer would be a no as they still provide a cost-effective alternative to the general public, so their overall benefit outweighs the negatives. What should be handled is the level of transparency of these services. They should only offer what they can deliver and not create unrealistic narratives about their nature.

\section{AI AND THE JUSTICE SYSTEM}

There is an Israeli study about what affects judges' verdicts which concluded that judges deliver much harsher decisions when they are hungry. ${ }^{79}$ This study has become somewhat famous when it comes to debates about fairness in human-judges' decisions. The reason is quite simple. The outcome of the study and many other examples through history led to the sentiment that robojudges could eradicate all human biases, be it intentional or accidental, and make sure that everybody is equal under the law..$^{80}$

This sentiment soon became overshadowed by the findings concerning the algorithmic and data bias. As mentioned, AI should not be automatically deployed in all areas of law. And judiciary is a particularly sensitive branch to put our trust into a black box. Moreover, even impartially, which is what made this deployment so appealing, seems to be a myth. As long as there is a bias in the code and the data, the decisions may be flawed. This risk was well demonstrated by the recent case in the US, State v. Loomis. The defendant, Eric Loomis, was sentenced based on the outcome provided by the software called COMPAS that concluded a risk assessment on Loomis. This assessment determined that Loomis was at high risk of recidivism. Based on this assessment, the defendant was

79 Danzinger, S., Levav J. and Avnaim-Pesso, L. (2011) Extraneous factors in judicial decisions. Proceedings of the National Academy of Sciences of the United States of America, 108 (17).

80 Tegmark, M. (2018) Life 3.0: Being Human in the Age of Artificial Intelligence, Penguin Books, p. 105. 
sentenced to six-year imprisonment and five-year extended supervision. ${ }^{81}$ The decision later served as a controversial point and led to a debate about these algorithms' nature and their accuracy. The issue concerning COMPAS become even more severe after a non-profit organization, ProPublica, conducted a study in which they observed 7000 defendants that COMPAS marked as high risk only to find out that just 20 per cent of them committed a relapse. Moreover, the study found out grave racial disparities - black defendants were falsely labelled as high risk, almost twice the rate as white defendants. ${ }^{82}$

This is not to say that AI cannot help the judiciary and make it more efficient. Generally, AI can be used in two ways in the judiciary - either as an independent adjudicating entity or as an assisting tool for a judge. ${ }^{83} \mathrm{AI}$ can also make the judicial proceedings faster and thus more effective the same way other AI tools help attorneys in their practice. ${ }^{84} \mathrm{AI}$ may very well work as a supportive tool since the tools offered for practicing attorneys can be deployed in the judiciary as well.

However, once we focus on more complex tools that are not designed to simply draft or review documents but are designed to actually make certain predictions or even decisions, we stand before the important question should we put our trust in them? And would it make justice fairer? Or even - just fair? In my opinion, and given the risks of AI, the technology has still not reached that level of transparency (or explainability) that an AI tool should be used to make crucial decisions in the field of justice. The issue of discrimination, algorithmic bias, legal and technical black box lead to many doubts about whether any use of artificial intelligence would not undermine the right to a fair trial. ${ }^{85}$ Moreover, some studies found out that humans tend to blindly trust machines, although they know they might be faulty. ${ }^{86}$ This could be particularly dangerous as many would not even question the outcome of these algorithms, which is exactly what happened in the Loomis case.

${ }^{81}$ Liu, H., Lin, C. and Chen, Y. (2018) op. cit., pp. 126-129.

82 Angwin J. and Larson J., Machine Bias. Propublica. 23 May 2016. Available from: https://www.propublica.org/article/machine-bias-risk-assessments-in-criminal-sentencing [Accessed 10 March 2021].

83 Dymitruk, M. (2018) The Right to a Fair Trial in Automated Civil Proceedings. Masaryk University Journal of Law \& Technology, vol 13 (1), p. 29.

${ }^{84}$ Dymitruk, M. (2018) op. cit., pp. 36-37.

85 Liu, H., Lin, C. and Chen, Y. (2018) op. cit., p. 137.

${ }^{86}$ Dymitruk, M. (2018) op. cit., pp. 31-32. 
Of course, humans are biased, too. They are prone to emotions, and they have bad days. ${ }^{87}$ However, is replacing one bias with another for the sake of effectivity something we should desire? As Fabian notes,

"At this point of our evolution and their development, we must not forget that judging requires not only knowledge of the law and case evidence, but also the empathetic ability to understand the emotions and motivations underlying human behaviour " 88

This is something we should bear in mind while implementing the algorithms into our justice system. Because deep underneath, a "human" understanding, empathy and capability of critical thinking is something a person might be looking for in our justice system along with the objectivity, once they are put on atrial. This may be particularly important when it is necessary to moderate too harsh a provision of law. And that is something the AI does not possess at the moment.

\section{CONCLUSION}

At the most general level. AI-based legaltech represents the conflict of whether to advance law further through the use of new disruptive technologies or whether to choose a "safe" path and remain conservative under the weight of possible risks. This paper discussed the present use of AI-based legaltech while addressing several critical points connected to the risks associated with artificial intelligence. At present, we can see several AI-based tools deployed in the legal profession. Some of them are research and review tools designed to help lawyers in their profession; others are chatbots and automated legal document generators created to provide cheaper access to law and justice. The technological innovations did not even miss the judicial field as there are attempts to apply AI-based technological solutions even in this field. Furthermore, despite the fact that AI-based legaltech can improve the legal profession, there are still many concerns that need to be addressed and further dealt with to make the present technological solutions more transparent.

The first part of this article focused on several issues concerning artificial intelligence, such as the technical and legal black box, algorithmic and data bias and discrimination. In the second part, the paper addressed the specific

87 Fabian, S. (2020) op. cit., p. 5.

88 Fabian, S. (2020) op. cit., p. 6. 
issues that arise from the application in the sphere of the provision of legal services and deployment in the judiciary. Many of the tools have drawn the attention of several stakeholders. Either be it academics or regulatory bodies who point out certain risks or bar associations, which are trying to delineate where the provision of legal services starts under the disguise of protection. Therefore, services such as LegalZoom in the US or SmartLaw in Germany have faced being sued for the unauthorized provision of legal services.

As demonstrated in the article, artificial intelligence could make the legal profession more efficient. The aim of this article was not to discourage lawyers or consumers from using legaltech but to merely state certain risks for them not to overly rely on the technology. All the remarks made showed that artificial intelligence could be a valuable tool; however, it must be used cautiously. The technology bears many risks which must be addressed before we put our blind trust into them.

\section{LIST OF REFERENCES}

[1] Angwin J. and Larson J., Machine Bias. Propublica. 23 May 2016. Available from: https://www.propublica.org/article/machine-bias-risk-assessments-in-criminalsentencing [Accessed 10 March 2021].

[2] Bathaee, Y. (2018) The Artificial Intelligence Black Box and the Failure of Intent and Causation. Harvard Journal of Law \& Technology, 31 (2).

[3] Calo, R. (2018) Artificial Intelligence Policy: A Primer and Roadmap. University of Bologna Law Review, 3 (2).

[4] Castelvecchi, D. (2020) Is facial recognition too biased to be let loose?. [online] nature. Available from: https://www.nature.com/articles/d41586-020-03186-4 [Accessed 5 March 2021].

[5] Cleland, S. (2011) Google's "Infringenovation" Secrets [online] Forbes. Available from: https://www.forbes.com/sites/scottcleland/2011/10/03/googles-infringenovationsecrets/?sh=5e00d3c930a6 [Accessed 5 June 2021].

[6] Corrales, M., Fenwick, M., Haapio H. and Vermeulen, E. (2019) Tomorrow's Lawyer Today? Platform-Driven LegalTech, Smart Contracts \& the New World of Legal Design. Journal of Internet Law. 
[7] Danzinger, S., Levav J. and Avnaim-Pesso, L. (2011) Extraneous factors in judicial decisions. Proceedings of the National Academy of Sciences of the United States of America, 108 (17).

[8] Dastin, J. (2018) Amazon scraps secret AI recruiting tool that showed bias against women. [online] Reuters. Available from: https://www.reuters.com/article/us-amazon-comjobs-automation-insight-idUSKCN1MK08G [Accessed 5 March 2021].

[9] Davis J. P. (2019) Artificial Wisdom? A Potential Limit on AI in Law (and Elsewhere). Oklahoma Law Review, 72 (1).

[10] Day, M. (2018) How LinkedIn's search engine may reflect a gender bias. [online] The Seattle Times. Available from: https://www.seattletimes.com/business/microsoft/howlinkedins-search-engine-may-reflect-a-bias/ [Accessed 5 March 2021].

[11] DoNotPay. Features. [online] Available from: https://donotpay.com [Accessed 5 March 2021].

[12] Dymitruk, M. (2018) The Right to a Fair Trial in Automated Civil Proceedings. Masaryk University Journal of Law \& Technology, vol 13 (1).

[13] European Commission (2020) White Paper On Artificial Intelligence - A European approach to excellence and trust, $\operatorname{COM}(2020) 65$ final, 19 February 2020. Available from: https://ec.europa.eu/info/sites/info/files/commission-white-paper-artificialintelligence-feb2020_en.pdf [Accessed 5 March 2021].

[14] Fabian, S. (2020) Artificial Intelligence and the Law: Will Judges Runs on Punchcards?. Common Law Review, 16 (4).

[15] Hao, K. (2020) The coming war on the hidden algorithms that trap people in poverty. [online] MIT Technology Review. Available from: https:/www.technologyreview.com/2020/12/04/1013068/algorithms-create-a-povertytrap-lawyers-fight-back// [Accessed 5 June 2021].

[16] Kaczorowska, M. (2019) Blockchain-based Land Registration: Possibilities and Challenges. Masaryk University Journal of Law and Technology, 13 (2).

[17] Katz, D. (2012) Quantitative Legal Prediction--or--How I Learned to Stop Worrying and Start Preparing for the Data-Driven Future of the Legal Services Industry. Emory Law Journal, 62 (4), p. 940. 
[18] Knight, W. (2017) The Dark Secret at the Heart of AI. [online] MIT Technology Review. Available from: https://www.technologyreview.com/2017/04/11/5113/the-dark-secretat-the-heart-of-ai/ [Accessed 5 June 2021].

[19] Krieger, M. (2019) Stanford student's quest to clear parking tickets leads to "robot lawyers. [online] The Mercury News. Available from: https://www.mercurynews.com/201 9/03/28/joshua-browder-22-builds-robot-lawyers/ [Accessed 5 March 2021].

[20] Lancaster, Alaina. Judge Rejects ROSS Intelligence's Dismissal Attempt of Thomson Reuters Suit Over Westlaw Content. [online] Law.com. Available from: https://www.law.com/therecorder/2021/03/29/judge-rejects-ross-intelligencesdismissal-attempt-of-thomson-reuters-suit-over-westlaw-content/ [Accessed 5 June 2021].

[21] LegalZoom.com, Inc. v. N.C. State Bar (2014), No. 11CVS15111, WL 1213242, North Carolina Business Court.

[22] Liu, H., Lin, C. and Chen, Y. (2018) Beyond State v. Loomis: Artificial Intelligence, Government Algorithmization, and Accountability. International Journal of Law and Information Technology, 27 (2).

[23] Marchant, G. (2017) Artificial Intelligence and the Future of Legal Practice. The SciTech Lawyer, 14 (1).

[24] McGinnis J. and Pearce, R. (2014) The Great Disruption: How Machine Intelligence Will Transform the Role of Lawyers in the Delivery of Legal Services. Fordham Law Review, 82 (6), p. 3042.

[25] Mokhtarian, E. (2018) The Bot Legal Code: Developing a Legally Compliant Artificial Intelligence. Vanderbilt Journal of Entertainment and Technology Law, 21 (1).

[26] Moradian, J. (2020) A New Era of Legal Services: The Elimination of Unauthorized Practice of Law Rules to Accompany the Growth of Legal Software. William. \& Mary Business Law Review, 12 (1).

[27] Morse, S. C. (2019) When Robots Make Legal Mistakes. Oklahoma Law Review, 72 (1).

[28] Niller, E. Can AI Be a Fair Judge in Court? Estonia Thinks So. [online] Wired. Available from: https://www.wired.com/story/can-ai-be-fair-judge-court-estonia-thinks-so/ [Accessed 26 February 2021].

[29] Pasquale, F. (2019) A Rule of Persons, Not Machine: The Limits of Legal Automation. George Washington Law Review, 87 (1). 
[30] Pasquale, F. (2020) Revisiting the Black Box Society by rethinking the political economy of big data. Big Data \& Society, 7 (2), p. 3.

[31] Poppe, E. (2019) The Future Is Complicated: AI, Apps \& Access to Justice. Oklahoma Law Review, 72 (1).

[32] Prins, C. and van Ettekoven, B-J. (2018). Data analysis, artificial intelligence and the judiciary system. In Mak V., Tjong Tjin Tai E., \& Berlee A. (Eds.), Research handbook in data science and law, Edward Elgar.

[33] Sandvik, K. (2021) Is Legal Technology a New "Moment" in the Law and Development Trajectory? [online] Antipode Online. Available from: https://antipodeonline.org/2019/ 12/04/legal-technology-law-and-development/ [Accessed 26 February 2021].

[34] Scherer, M. (2016) Regulating Artificial Intelligence Systems: Risks, Challenges, Competencies, and Strategies. Harvard Journal of Law \& Technology, 29 (2).

[35] Schneider, G. (2018) European intellectual property and data protection in the digitalalgorithmic economy; a role reversal(?). Journal of Intellectual Property Law \& Practice, 13 (8).

[36] Semmler, S. and Zeeve, R. (2017) Artificial Intelligence: Application Today and Implications Tomorrow. Duke Law \& Technology Review, 16.

[37] Shipman, C. (2019) Unauthorized Practice of Law Claims Against LegalZoom - Who Do These Lawsuits Protect, and is the Rule Outdated?. Georgetown Journal of Legal Ethics, 32 (4).

[38] Sourdin, T. (2018) Judge v Robot? Artificial Intelligence and Judicial Decision-Making. UNSW Law Journal, 41 (4).

[39] Tegmark, M. (2018) Life 3.0: Being Human in the Age of Artificial Intelligence, Penguin Books.

[40] Wendel, B.W. (2019) The Promise and Limitations of Artificial Intelligence in the Practice of Law. Oklahoma Law Review, 72 (1).

[41] Wischmeyer, T. (2020) Artificial Intelligence and Transparency: Opening the Black Box. In Wischmeyer, T. and Rademacher T. (Eds.), Regulating Artificial Intelligence, Springer.

[42] Yu, R. and Spina G.A. (2019) What's Inside the Black Box? AI Challenges for Lawyers and Researchers. [online] Cambridge University Press. Available from: https://www.cambridge.org/core/journals/legal-information- 
management/article/whats-inside-the-black-box-ai-challenges-for-lawyers-andresearchers/8A547878999427F7222C3CEFC3CE5E01\#article [Accessed 29 May 2021].

[43] Zednik, C. (2019) Solving the Black Box Problem: A Normative Framework for Explainable Artificial Intelligence. [online] Philosophy \& Technology. Available from: https://doi.org/10.1007/s13347-019-00382-7 [Accessed 29 May 2021].

[44] 33 O 35/19, LG Köln, 8.10.2019.

[45] I-6 U 263/19, Oberlandesgericht Köln, 19.6.2020. 